\title{
A Novel HBA1 Gene Polymorphism in Vietnamese Population: C.172G>A (P. Gly58Ser)
}

\author{
Lý Thị Thanh Hà ${ }^{1 \#}$, Đinh Phương Nhung1" , Nguyễn Văn Hưng ${ }^{1}$, Đỗ Phước Huy ${ }^{1}$, Bùi Thi Phương \\ Hoa $^{1}$, Trần Thị Thanh Huyền ${ }^{1 *}$ and Tien AnhNgo ${ }^{2 *}$ \\ ${ }^{1}$ Department of Medical Genetics, Vinmec Health Care System, Vietnam \\ ${ }^{2}$ Vinmec Tissue Bank, Vinmec Health Care System, Vietnam \\ \#These authors have contributed equally to this work as first authors.
}

*Corresponding author: Tien Anh Ngo, Vinmec Tissue Bank, Vinmec Health Care System, Vietnam.

Trần Thị Thanh Huyền, Department of Medical Genetic, Vinmec Health Care System, Vietnam.

To Cite This Article: Lý Thị Thanh Hà, Đinh Phương Nhung, Nguyễn Văn Hưn, Đỗ Phước Huy, Bùi Thi Phương Hoa, Trần Thị Thanh Huyền and Tien AnhNgo. A Novel HBA1 Gene Polymorphism in Vietnamese Population: C.172G>A (P. Gly58Ser). Am J Biomed Sci \& Res. 2021 - 12(5). AJBSR. MS.ID.001790. DOI: 10.34297/AJBSR.2021.12.001790.

Received: 眥 April 19, 2021; Published: 䟱 April 30, 2021

\begin{abstract}
Currently, over 363 mutations in HBA1 gene, including hemoglobin variants, have been reported. This study reports a novel HBA1 gene polymorphism: c.172G>A (p. Gly58Ser) in a Vietnamese male. This polymorphism is essential from a clinical and genetic counseling point of view.

Keywords: Thalassemia, HBA1 gene, Polymorphism

Abbreviations: Hb: Hemoglobin; MCH: Mean Corpuscular Hemoglobin; MCV: Mean Corpuscular Volume; RBC: Red blood cell count; IVF: In Vitro Fertilization
\end{abstract}

\section{Introduction}

Thalassemia is one of the most common autosomal recessive disorders, with a carrier prevalence of 5\% globally [1]. This disorder is the primary cause of hemolytic anemia worldwide, especially in Southeast Asian countries, including Vietnam. There are two main types of thalassemia, including Alpha thalassemia (causing by mutations in alpha-globin gene) and Beta-thalassemia (causing by mutations in beta-globin gene) [2]. Mutations in the a globin gene include large deletions and point mutations. SEA deletion is a widespread significant mutation in Vietnam, clearly shown in the subclinical results. However, clinical manifestations of non-deletional mutations in alpha thalassemia are varied, and some cases may have a more severe phenotype than deletional forms of alpha thalassemia [3]. Thus, discovering novel variants in the $\alpha$ globin gene and genotype-phenotype correlation studying will contribute to the genetic counseling and treatments [4]. More than 363 mutations, including hemoglobin variants, have been reported in the HBA1 gene [5]. In this study, a novel HBA1 gene polymorphism is reported in a Vietnamese male.

\section{Material and methods}

An unrelated couple in the Vietnamese Kinh group was admitted to the Medical Genetics Department, Vinmec HealthCare System, for genetic counseling for thalassemia. They had a first healthy baby but were at risk of secondary infertility. They visited the IVF Center, Vinmec Times City International Hospital, and were recommended to be at risk of being of thalassemia carrier and conduct genetic testing for diagnosis. Based on screening tests, including complete blood count and hemoglobin electrophoresis (Table 1), the wife has a HbE carrier but cannot exclude having an alpha-globin gene mutation. In contrast, her husband does not show any symptoms of anemia but has not yet excluded the $\alpha$ globin gene mutation. 
Table 1: Hematological parameters.

\begin{tabular}{|c|c|c|}
\hline Parameters & Husband & Wife \\
\hline Age (years) & 37 & 38 \\
\hline Hb (g/dL) & 134 & 121 \\
\hline MCV (fL) & 83.4 & 78.6 \\
\hline MCH (pg) & 27.5 & 26.1 \\
\hline HbA (\%) & 98.2 & 73.9 \\
\hline HbA2 (\%) & 1.8 & \\
\hline HbX (\%) & & HbE: 23, HbF: 3.1 \\
\hline RBC (x106/uL) & 4,53 & 4.49 \\
\hline Inclusion bodies & Negative & Negative \\
\hline
\end{tabular}

To eliminate the risk of having a baby with alpha thalassemia, they are assigned to test for 21 common mutations in the $\alpha$ globin gene. $\alpha$-Globin Strip assay Ref 4-160 (Vienna lab) was used to detect 21 a globin mutations including: -3.7, -4.2, --MED, --SEA, --THAI, --FIL, --20.5 kb, anti-3.7, a1 cd 14 [TGG>TAG], $\alpha 1 \mathrm{~cd} 59$ [GGC>GAC] (Hb Adana), $\alpha 2$ init cd [ATG>ACG], $\alpha 2$ cd 19 [-G], $\alpha 2$ IVS1 [-5nt], $\alpha 2$ cd 59 [GGC>GAC], $\alpha 2$ cd 125 [CTG>CCG] (Hb Quong Sze), $\alpha 2$ cd 142 [TAA>CAA] (Hb Constant Spring), $\alpha 2$ cd 142 [TAA>AAA] (Hb Icaria), $\alpha 2$ cd 142 [TAA>TAT] (Hb Pakse), $\alpha 2$ cd 142 [TAA>TCA]
(Hb Koya Dora), $\alpha 2$ poly A-1 [AATAAA-AATAAG], $\alpha 2$ poly A-2 [AATAAAAATGAA] [6].

Sanger sequencing was then performed to confirm these results. Amplification products generated by PCR were purified using PureLink ${ }^{\mathrm{TM}}$ PCR Purification Kit (Invitrogen) and were cycle sequenced using Big Dye v3.1 reagent (Applied Biosystems) according to the manufacturer's protocol. Sequencing products were purified with Big Dye XTerminator ${ }^{\mathrm{TM}}$ Purification Kit (Applied Biosystems) and automated sequencing performed by capillary electrophoresis on an ABI3500Dx (Applied Biosystems). Sequences were aligned and examined by using Chromas Pro software (Technelysium Pty Ltd).

\section{Results and Discussion}

With the $\alpha$-Globin Strip Assay ${ }^{\circledR}$ SEA kit, no common mutation was found in the Southeast Asian population. However, the husband's Strip assay results have no signal of probe control a1 CD59 (Figure 1). We suspected that there is an abnormality at the location of the a1 CD59 probe. We, therefore, decided to do sequencing the HBA1 gene to elucidate this. The HBA1 gene sequencing result of the wife's sample and a commercial control sample were conducted concurrently with the husband's sample. Results of Sanger sequencing are shown in Figure 2.
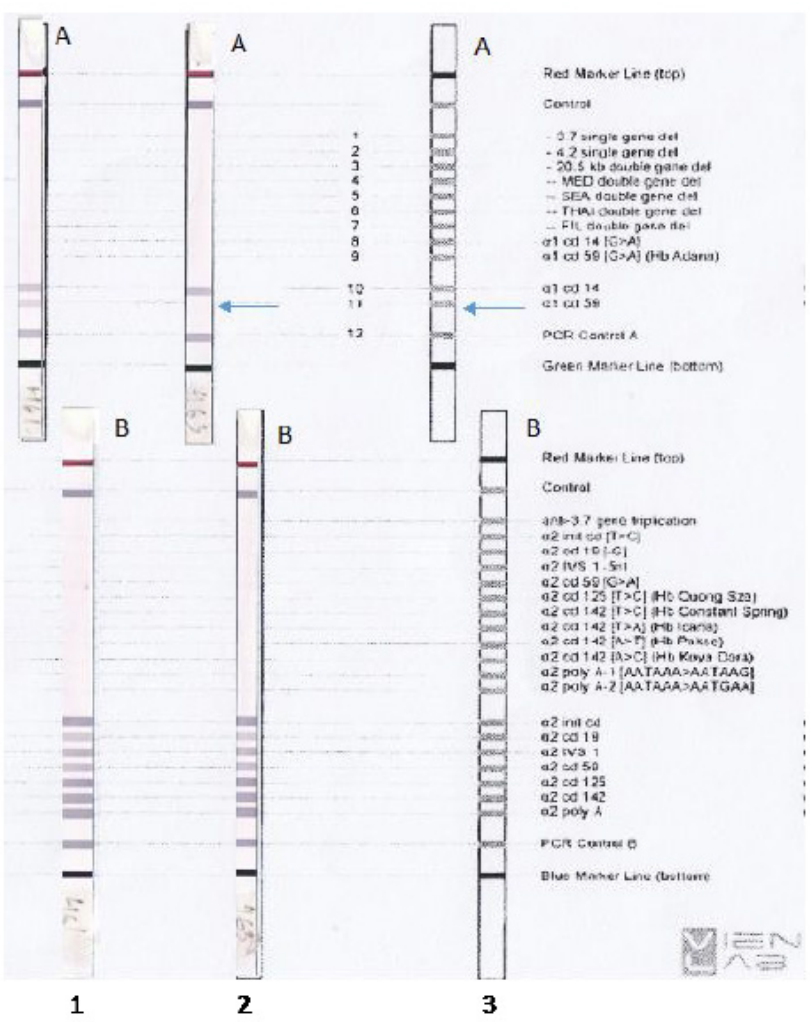

Figure 1: Result of mutations screening using $\alpha$-Globin Strip Assay®SEA kit. A: Strip A, B: Strip B. Line 1. Wife: No mutation detected.

Line 2. Husband: No mutation detected, but Strip assay result has no signal of probe a1 CD59.

Line 3. Reference marker. 


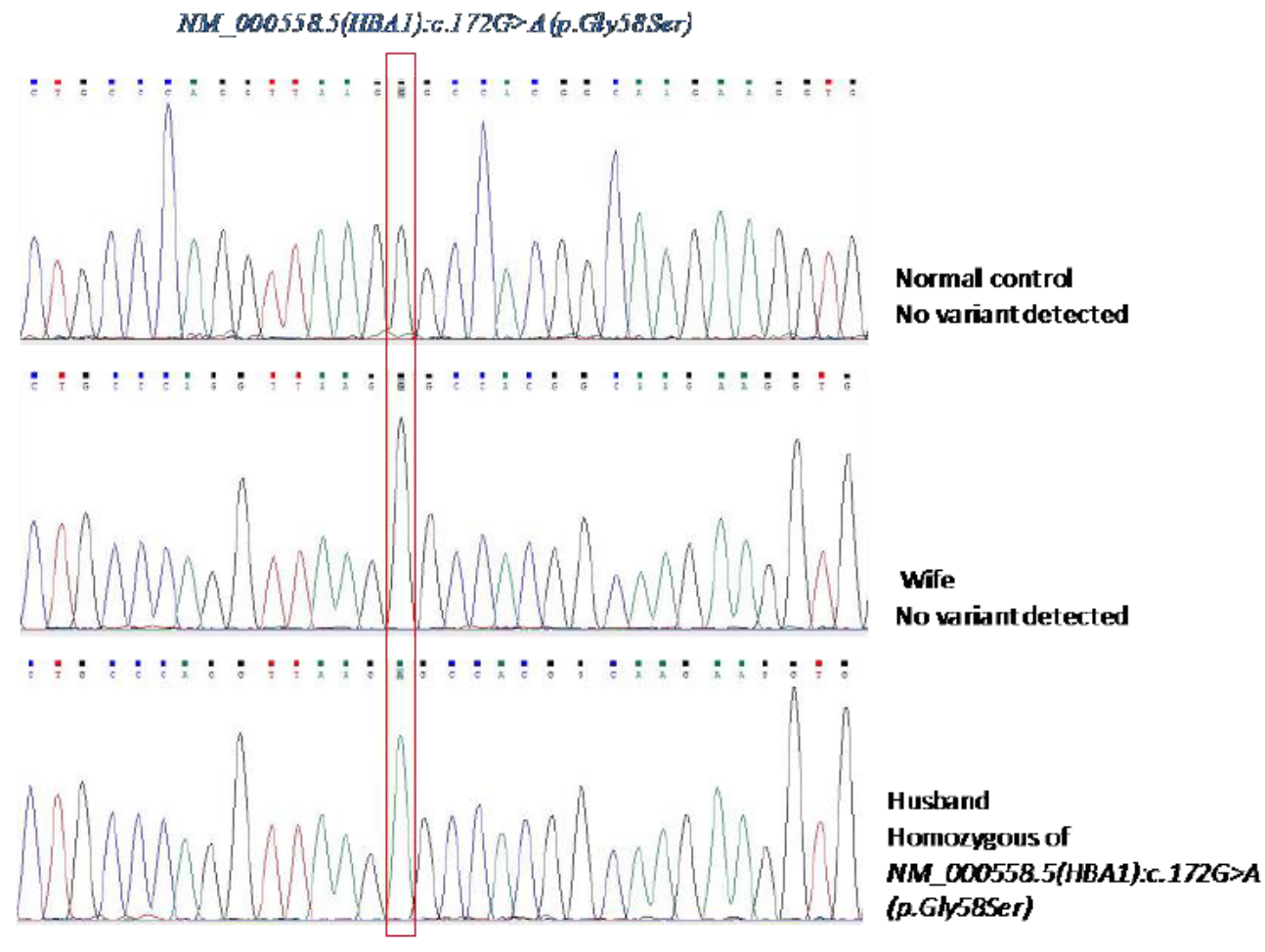

Figure 2: Detection and confirmation of the novel polymorphism by Sanger sequencing; Result from $\mathrm{HbA} 1$ gene sequencing.

Sanger sequencing results showed that the husband's sample appeared homozygous of HBA1: c.172G>A (p. Gly58Ser). We analyzed 300 healthy individuals retrospectively. None of them had this polymorphism. $\alpha$ globin gene HBA1: c.172G>A (p. Gly58Ser) alteration is a single nucleotide polymorphism resulting in protein alteration. This polymorphism was not previously reported and cannot be found in the $\alpha$ globin gene database [5]. Importantly, although the husband carries the HBA1: c.172G>A (p. Gly58Ser) in a homozygous state, he does not have anemia. His hematological and hemoglobin data suggest that this novel polymorphism does not alter the maturation of pre- mRNA and does not have any effects on the hematological values. Several mutations associated with mild or severe alpha-thalassemia have been described at this gene region, such as HBA1: c.171G>C, HBA1: c.172G>C [5].

\section{Conclusion}

Briefly, to provide reliable genetic counseling and then treatment direction, it is essential to report altered nucleotides (variable or polymorphism) and indicate the clinical phenotype's relationship. Simultaneously, pay special attention to race and geography because the phenotypic expression is the result of interactions between genes, environmental effects, and other factors.

\section{Acknowledgments}

The authors express our sincere to all staff of the Laboratory Department, IVF center, Vinmec Times city International Hospital, and Vinmec Tissue Bank.

\section{Conflict of Interest}

The authors declare no conflicts of interest.

\section{References}

1. Modell Bernadette, Matthew Darlison (2008) Global epidemiology of haemoglobin disorders and derived service indicators. Bull of the World Health Organization 86(6): 480-487.

2. K Tari, P Valizadeh Ardalan, M Abbaszadehdibavar, A Atashi, A Jalili, et al. (2018) Thalassemia an update: molecular basis, clinical features and treatment. International Journal of Biomedicine and Public Health 1(1): 48-58.

3. I Kalle Kwaifa, MI Lai, S Md Noor (2020) Non-deletional alpha thalassaemia: A review. Orphanet J Rare Dis 15(1): 166.

4. S Thakur, S Singh (2019) Genetic counseling to prevent thalassemia and hemoglobinopathy in the Indian population. Perinatology 20(3): 61-65.

5. HbVar: A database of Human Hemoglobin Variants and Thalassemias, USA.

6. Thalassemia, ViennaLab. 